\title{
Study on Application of Computer Technology in Education Management
}

\author{
Siqin $\mathrm{CaO}^{1, \mathrm{a}}$ \\ ${ }^{1}$ Nanchang Institute of Science \& Technology, Nanchang, Jiangxi, 330108 \\ a email
}

Keywords: Computer Technology, Education Management, Applied Research

\begin{abstract}
With the continuous development and progress of modern science and technology, more and more widespread application of computer technology, more and more involved in its industry wide. Especially in teaching management education in China, with computer technology integration, and constantly so that the quality and efficiency of teaching our teaching has been effectively improved, but also to enhance the management level of education has played a significant role in promoting. In this paper, a brief analysis of the application of computer technology in education management, hoping to bring some help for our current education management efficiency improvement.
\end{abstract}

\section{Introduction}

With the current information technology, more and more popularity and the continuous development and innovation, the application of computer technology in the teaching of management education in more depth. And sufficient in the field of education in the use of computer technology, not only by means of computer technology allows multimedia, digitization and networking goals of education can be achieved, but also to make our teaching management efficiency greatly enhance the level for our modern economic development, producing more information technology personnel, nationals of China has been to enhance the quality of information, thus promoting the development of China's information construction.

\section{Application of Computer Technology in Education Management}

From the moment in terms of education and teaching management processes, each course has been the assessment of the quality of teaching in our education need to be resolved important work, research and analysis of traditional teaching assessment work to do, and marking papers to bring the majority of staff a huge workload and HIA presence of low efficiency problem, to some extent, this phenomenon is teaching school workers caused great difficulties in teaching, but also to the school's human and financial resources caused a great burden. Through the application of computer technology, not only can be constructed out of a database, but also be able to use computers to analyze and marking papers, so that scoring efficiency has been greatly enhance the level, while also reducing the teaching staff of the labor intensity to a certain extent [1]. In addition, by means of computer-related technology is also able to build up test library management system and, thus, the quality of each course so that the proposition has been effectively improved, prompting questions related to issues of more objective, which means it will be able to teaching and assessment requirements and phase anastomosis.

From the perspective of the teaching work speaking in the teaching work, and ultimately the quality of classroom teaching is very important. For now, China's major colleges and universities more comprehensive and rapid evaluation of classroom teaching quality assessment and disciplines, building out computer classroom teaching quality evaluation system. All are able to promote the systematic evaluation of classroom teaching quality of schools, so as to continuously so that all teachers and students to actively participate in classroom teaching are fully mobilized, but also let the school management level has been further improved. Conventional classroom teaching quality evaluation of the relative ratio, almost computer applications, so that the traditional manual 
evaluation of the error rate has been reduced to a large extent, will be more realistic and effective management platform and a lot of feedback information to the educational administrators, classroom improve teaching, improve and expand the road construction education teaching quality has laid a solid foundation.

\section{The Library Management of Computer Technology in Education and Teaching of Application}

Traditional library management model for the students to view reading is very inconvenient, students need a bookshelf to look to a bookshelf, students will not only cause great inconvenience Buyers reading, but also waste a lot of time. Plus the number of rare books, prompting many students' reading needs are difficult to be effectively met through the application of computer technology, it is possible to build up a library information database, which by means of a network platform, will be able to make library resources become more abundant and diversified. In addition, the application of computer technology is also able to be more humane, convenient services to the inspection of the books the teachers and students, students and teachers of reading needs are more fully met. In addition, through the use of computer technology, but also by means of the network platform for a variety of library resource sharing purpose is achieved, it will not only allow students to get a broader vision and a wealth of resources for reading, but also to a certain extent, reduce the uplink school books purchase cost.

By means of the application of computer technology, it is possible to build a computer database of books out, so students will be able to make their leisure time more colorful [2]. Students through the rational use of spare time, can tap into more and more abundant resource library books, so that students get to expand the horizons of knowledge, encourage students can not learn in books of knowledge can be filled, so that students' learning is effectively promoted. In addition, the majority of teachers as a teaching workers who could go to the aid of a computer database of books and constantly improve their own innovative teaching methods and knowledge base to enable it to keep up with the development of education and the development trend of the times, and to do the times, which means it will be able to make their own to further enhance the level of teaching, the content will be more abundant knowledge imparted to students, so that students throughout the learning level can be effectively improved.

\section{Limitations of Computer Technology in Educational Practice}

With the continuous development and progress of science and technology, the computer technology in teaching the increasingly popular field of education, but also for teaching quality and enhance Shuibo a big help, so that the quality of teachers and the quality of the teaching workers also or have obtained the appropriate development and upgrading, so that students' interest in learning and learning initiative has been fully stimulate and nurture. However, on the current situation, most students in the teaching process of the application of computer technology is not very comprehensive, based on the application and did not get into teaching content corresponding shift effect, but in the teaching process, classroom teaching mode innovation and change [3]. In computer projectors used in the process, mostly in the form of the conventional classroom lectures clips, taught by playing in place of spoken language teaching, although this teaching model for students to produce a certain interest, but most of them are curious about new teaching mode, and for teaching contents have not changed much, the computer did not allow exploratory, collaborative characteristics into full play, it does not let the teaching efficiency is improved radically, and for schools, also did not play expected to substitute teaching management effectiveness. Therefore, only the correct blend of computer technology and education management, so that the overall level of education in order to get promoted. Schools should be high on the computer technology and curriculum integration efforts were gradually continue to strengthen, promote computer technology can enhance teaching efficiency is becoming an effective auxiliary teaching tool. In addition, it should be combined with the direction and goals that will integrate various methods suitable for different stages of education computer application technology worked out in order to build better 
used in education and teaching management in computer-related management techniques.

For now, the majority of our schools are actively integrate computer technology and teaching practices between work, but in practice but lack of appropriate application of environmental education. Directed to this phenomenon, only the advanced hardware and software infrastructure conditions for building up resources to achieve management objectives from the planning concept on the basis of open education. By applying computer technology to build the campus network platform for schools, teachers and students to create a safe, stable teaching and learning platform [4]. Thereby not only allows teachers office digital, network, and also allows knowledge of teaching has been to expand and improve the teaching methods, so that students 'learning initiative, enthusiasm has been fully mobilized, so that students' interest and subjective initiative is fully excited, which means it will be able to make teaching efficiency and quality has been effectively improved, promote the rapid development of China's educational undertakings.

\section{Conclusion}

In summary, with the continuous development of computer technology and innovation in the field of education in the extensive use of computer technology has become the inevitable trend of the times, but also to make the quality of teaching and the education level of the education sector has been further optimized and upgrade, so as to promote the healthy and stable development of China's education, as the current development of our society producing more comprehensive information technology personnel.

\section{References}

[1] Liu Yanfeng. Application of Computer Assisted Instruction in Higher Vocational Education [J]. Science Technology and Industry, 2010, 02: 110-116.

[2] Sun Chunli, Lin Xiaoling. Application of computer technology in secondary vocational education teaching [J]. Health Vocational Education, 2014,04: 44-46.

[3] Li Huaicheng, Li Wenhua, Hu Huaijin. Modern Education Technology Application in my school computer teaching and improvement measures [J]. South China University of Tropical Agriculture, 2015, 01: 77-80.

[4] Peng Kanghua. An Analysis of Higher Education and Teaching Management application information in computer information technology [J]. Information and Computer (Theory Edition), 2011,08: $215+217$. 